\title{
Facilitadores e barreiras no processo de inclusão escolar de crianças com necessidades educativas especiais: a percepção das educadoras*
}

\section{Facilitators and barriers in the process of school inclusion of children with special educational needs: the perception of the educators}

\author{
Paola de Mattos Ribeiro de Oliveira ${ }^{1}$, Letícia Rocha Dutra ${ }^{2}$, \\ Poliana Pires Torres Melo ${ }^{3}$, Márcia Bastos Rezende ${ }^{4}$
}

http://dx.doi.org/10.11606/issn.2238-6149.v26i2p186-193

\begin{abstract}
Oliveira PMR, Dutra LR, Melo PRT, Rezende MB. Facilitadores e barreiras no processo de inclusão escolar de crianças com necessidades educativas especiais: a percepção das educadoras. Rev Ter Ocup Univ São Paulo. 2015 maio-ago.;26(2):186-93.
\end{abstract}

RESUMO: A inclusão educacional ganhou força após a Declaração de Salamanca em 1994. Nesse contexto, toda criança, independente de sua condição, passou a ter direito de frequentar escolas regulares. Ao se considerar que cabe ao terapeuta ocupacional contribuir com o processo de inclusão, o presente estudo teve por objetivos conhecer a percepção dos professores sobre os facilitadores e as barreiras relacionadas ao processo de inclusão escolar de crianças com necessidades educativas especiais. $\mathrm{O}$ estudo qualitativo foi realizado entre fevereiro e dezembro de 2011, numa escola municipal de ensino infantil de Belo Horizonte, com dez educadoras que lecionavam para crianças deficientes. A amostra foi selecionada por conveniência, os participantes responderam a uma entrevista aberta, e os dados foram submetidos à análise de conteúdo. Foram definidas três categorias analíticas: "A inclusão sobre diversos olhares", "Não é por minha causa que a inclusão escolar não acontece" e "Eu faço a minha parte". O discurso das educadoras flagra uma diversidade de conceitos sobre inclusão escolar, sobre fatos que agem como dificultadores e sobre as estratégias que utilizam para contribuir com tal processo. Concluiu-se que para que ocorra uma transformação da realidade escolar e social, a inclusão escolar precisa ser entendida como uma filosofia em que haja participação de todos.

DESCRITORES: Terapia Ocupacional; Inclusão escolar; Educação.

Oliveira PMR, Dutra LR, Melo PRT, Rezende MB. Facilitators and barriers in the process of school inclusion of children with special educational needs: the perception of the educators. Rev Ter Ocup Univ São Paulo. 2015 May-Aug.;26(2):186-93.

ABSTRACT: The educational inclusion gained strength after the Salamanca Statement (1994). In this context, every child, regardless of their condition, became entitled to attend regular schools. Considering that it is the occupational therapist's responsibility to contribute to the process of inclusion, the objective of this study was to know the teachers' perception of the facilitators and barriers that are related to the process of school inclusion of children with special educational needs. The qualitative study was conducted between February and December 2011, in a childhood education public school of Belo Horizonte, with 10 educators who taught disabled children. The sample was selected by convenience, the participants responded to an open interview, and the data was subjected to content analysis. Three analytical categories were defined: "The inclusion in

\footnotetext{
* Trabalho de Conclusão de Curso, em formato de artigo científico, apresentado como exigência parcial para obtenção do título de Terapeuta Ocupacional à Universidade Federal de Minas Gerais (2012), sob orientação da professora Dra. Márcia Bastos Rezende; Trabalho apresentado na XIX Jornadas de Jovens Pesquisadores - Associação de Universidades do grupo Montevidéu - AUGM, Universidade Nacional Del Este Cidade Del Este, República do Paraguai, em 25, 26 e 27 de outubro de 2011, tendo recebido Menção Honrosa; Trabalho apresentado no Seminário de Inclusão Escolar: as contribuições da Terapia Ocupacional. Desafios da parceria da Terapia Ocupacional: foco na consultoria. 2011; Trabalho apresentado no XI Congresso Brasileiro de Terapia Ocupacional. 2009.

1. Terapeuta ocupacional graduada pela Universidade Federal de Minas Gerais.

2. Bolsista de pós-graduação do programa de Mestrado Profissional Ensino em Saúde da Universidade Federal dos Vales do Jequitinhonha e Mucuri. Terapeuta ocupacional graduada pela Universidade Federal de Minas Gerais.

3. Terapeuta ocupacional graduada pela Universidade Federal de Minas Gerais.

4. Terapeuta ocupacional, Doutora em Ciências Biológicas, Professora Adjunta do Departamento de Terapia Ocupacional, UFMG. Endereço para correspondência: Paola Mattos de Oliveira. Rua Ovídio, 193. Belo Horizonte, MG, Brasil. CEP: 30880-100. E-mail: paolaoliveira.to@gmail.com.
} 
different views", "It's not because of me that the school inclusion does not happen", and "I do my part". The speech of the educators expose a diversity of concepts about school inclusion, about facts that act as hinderers, and about the strategies they use to contribute to this process. It was concluded that for there to be a transformation of

\section{INTRODUÇÃO}

$\mathrm{A}$ inclusão escolar ganhou relevância no cenário mundial após a Declaração de Salamanca‥ Esse documento, dentre outras questões, propõe que as escolas regulares devem incluir as crianças com necessidades educativas especiais, numa pedagogia centrada na criança, a fim de atender as suas necessidades ${ }^{2}$. $\mathrm{Na}$ Declaração, o princípio básico de inclusão escolar compreende que as escolas devem reconhecer e responder às diversas necessidades dos alunos e garantir-lhes educação de qualidade, que proporcione aprendizagem, utilizando todas as estratégias pertinentes ${ }^{1}$.

O Brasil, apesar de não ter assinado o documento, compartilha de sua proposta e busca aplicá-la por meio da Lei 9.394, de 20 de dezembro de 1996, que estabelece ser responsabilidade dos sistemas de ensino oferecer aos educandos currículos, métodos, técnicas, recursos e organização específicos a fim de atender as suas necessidades. Segundo o Ministério da Educação e Cultura, a inclusão implica a possibilidade de interação, acolhida, socialização, adaptação do indivíduo ao grupo e, sobretudo, da modificação da escola para atendê-lo ${ }^{3}$.

Em acordo com essa concepção, Vygotsky ${ }^{4}$ assinala que as pessoas com deficiência possuem potencialidades e capacidades, que requerem condições materiais e instrumentais adequadas para que se desenvolvam. A deficiência em si não incapacita, e é a somatória dos aspectos biológico e social que determina a evolução do sujeito. $\mathrm{O}$ estabelecimento da educação inclusiva é fundamental para construir uma sociedade mais justa. Isso implica a necessidade de se preocupar com a qualidade da educação e com o quanto essa inclusão escolar contribui para formar indivíduos críticos. Se a crítica se relaciona com a possibilidade de uma sociedade mais justa, o convívio com minorias discriminadas constitui elemento formador. Para essa formação, o papel do professor é fundamental, pois não se trata unicamente de transmitir conhecimentos, mas modificar a forma que se faz e sua relação com o saber. A forma de transmissão não se refere somente a técnicas, mas ao engajamento do professor, a sua responsabilidade com o aprendizado do aluno, isto é, refere-se a princípios políticos e éticos ${ }^{5}$. the school and social reality, school inclusion needs to be understood as a philosophy in which everyone participates.

KEYWORDS: Occupational Therapy; School inclusion; Education.

Para realizar a inclusão é necessária uma posição crítica dos educadores em relação aos saberes escolares e à forma como podem ser trabalhados; implica considerar que a escola não é uma instituição pronta e inflexível, mas uma estrutura que deve acompanhar o ritmo dos educandos, em um processo que requer diálogo dos professores com a comunidade escolar e com outros campos do conhecimento, a saber: campos da saúde, do desenvolvimento social; os movimentos de organização social da população; as universidades, centros de pesquisa, organizações não governamentais, entre outros. Segundo estudo de Ide et al. ${ }^{6}$, a inclusão da criança com necessidades educativas especiais (NEE) na escola também é objetivo da Terapia Ocupacional, na medida em que o ambiente escolar promove a experimentação de diversas atividades, que permitem o desenvolvimento global da criança, o desenvolvimento de habilidades e capacidades, a superação de dificuldades e a descoberta de que é parte integrante e atuante da sociedade. $\mathrm{O}$ ambiente escolar também deve possibilitar à criança aprender que o ambiente social é constituído de pessoas singulares que devem ser respeitadas.

Inclusão escolar não significa apenas a inserção física do aluno com necessidades educacionais especiais em um ambiente comum a todos. É necessário que o aluno seja parte do contexto escolar, o que significa participar ativamente de todas as atividades sociais e pedagógicas desenvolvidas. Existem especificidades na condição de deficiência que interferem no processo de ensino e aprendizagem. Nesse sentido, a atuação do terapeuta ocupacional no processo de inclusão escolar acontece de forma a munir o professor de conhecimentos e habilidades, visando fortalecer a ação do educador e do aluno, promovendo soluções para os impasses, a partir do próprio grupo, utilizando-se de diferentes adaptações nas atividades, adequadas às necessidades de cada realidade ${ }^{7}$. Acredita-se que o professor precisa desse apoio para lidar com a diversidade dos alunos ${ }^{8}$ e da definição de uma política que venha subsidiar princípios e práticas para as necessidades educativas especiais, construindo normas uniformes sobre a igualdade de oportunidades para as pessoas com deficiência ${ }^{9}$. Mesmo com todo o desenvolvimento social, encontramos nas escolas barreiras para a concretização dessa filosofia. A escola inclusiva apenas deixará o plano imaginário a partir de condições muito especiais de recursos humanos, pedagógicos e materiais. Focando o professor enquanto promotor da 
aprendizagem, faz-se necessário compreender sua percepção acerca dos facilitadores e barreiras que interferem no processo da inclusão escolar, para compreendermos o porquê de ainda existir uma prática distante em muitas escolas. Nesse contexto, o objetivo desse estudo é conhecer a percepção das professoras, de uma escola infantil da rede municipal da cidade de Belo Horizonte (Minas Gerais, Brasil), que apontará os facilitadores e as possíveis barreiras ao processo de inclusão escolar, a fim de construir estratégias coletivas para facilitar esse processo.

\section{PROCEDIMENTOS METODOLÓGICOS}

O presente estudo qualitativo foi realizado entre fevereiro e dezembro de 2011, com professores que atuam na rede Municipal de Educação Infantil de Belo Horizonte (MG, Brasil). A escolha do local se deve à demanda da escola e à parceria com a Universidade Federal de Minas Gerais. Foram utilizadas entrevistas semiestruturadas com questões abertas que dizem respeito à rotina das professoras, que têm crianças de inclusão em sua turma, e a concepção delas sobre a proposta da Inclusão escolar. A amostragem foi feita por saturação, ou seja, a suspensão de inclusão de novos participantes quando os dados obtidos passam apresentar, na avaliação do pesquisador, redundância ou repetição, pois as informações fornecidas por esses pouco acrescentam ao material já obtido, não mais contribuindo significativamente para o aperfeiçoamento da reflexão teórica fundamentada nos dados que estão sendo coletados $^{10}$. Paralelamente à coleta foi feita análise de conteúdo, muito utilizada nas pesquisas qualitativas, usando um conjunto de estratégias (leituras flutuantes, inferências e categorizações), cujo objetivo é a busca dos sentidos contidos em documentos, material coletado por meio de entrevistas e/ou notas de observação tomadas em diários de campo $^{11}$. O trabalho foi encaminhado ao Comitê de Ética em Pesquisa da Universidade Federal de Minas Gerais e aprovado no parecer $\mathrm{n}^{\circ} \mathrm{CAAE} 0263.0203-000-11$.

Participaram do estudo dez professoras da rede municipal de ensino infantil, que lecionam há no mínimo seis meses e que estão diretamente envolvidas com o processo de inclusão escolar de uma criança em sua turma. As entrevistas foram constituídas por cinco questões abertas utilizadas como um roteiro para o pesquisador. Este recurso possibilita obter informações mais específicas, contemplar todas as informações requeridas, além de o entrevistado ter maior liberdade para responder e ilustrar conceitos ${ }^{12}$. Ao iniciar as entrevistas, as educadoras foram informadas sobre a pesquisa e assinaram o Termo de Consentimento Livre e Esclarecido. Outro recurso utilizado durante a realização das entrevistas foi um diário de campo, no qual os pesquisadores documentaram as reações corporais e verbais de cada entrevistada. A técnica de observação é um dos componentes do trabalho de campo utilizado nas pesquisas qualitativas e pode auxiliar na análise dos dados ${ }^{12}$.

As professoras selecionadas foram questionadas quanto à rotina de suas salas considerando a presença de uma criança deficiente; quais estratégias são realizadas por elas para incluir essa criança em sua sala de aula; e o que facilita e/ou dificulta a inclusão dessa criança. As entrevistas foram realizadas individualmente em uma sala fechada onde se encontravam apenas as duas entrevistadoras (sendo uma com o diário de campo anotando as observações) e a entrevistada. Todas as falas foram gravadas, transcritas e lidas pelas entrevistadas.

Para interpretação das informações colhidas, foi utilizada a análise do conteúdo temático - já descrito -, que, segundo Turato ${ }^{12}$, procura nas expressões verbais ou textuais os temas gerais recorrentes que aparecem no interior de conteúdos mais concretos.

\section{RESULTADOS}

A partir da análise das informações coletadas, resultaram três categorias: "A inclusão sobre diversos olhares", "Não é por minha causa que a inclusão escolar não acontece" e "Eu faço a minha parte", que serão descritas a seguir.

\section{"A inclusão sobre diversos olhares"}

Nela as educadoras traduzem seu conceito de inclusão escolar e as atitudes vinculadas a ele. Observa-se durante a entrevista que duas das educadoras expressaram diferentes concepções sobre inclusão escolar associadas à integração e à inclusão social:

... estar inserindo P. o tempo todo nas atividades, nas quais ele está participando ativamente... adaptando para que ele se sinta como parte integrante do grupo...; “... não tenho problema com a inclusão dele, pois ele participa das brincadeiras, dos eventos... (E1), (E2)

As entrevistadas apontaram que o diagnóstico é fundamental para o manejo e para o processo de aprendizagem da criança:

... pedi ao médico para nos enviar um relatório com um diagnóstico definitivo para sabermos como trabalhar com ela dentro dessas limitações que ela apresenta... (E3). 
Outras educadoras formularam um conceito de inclusão implicado na socialização das crianças NEE com as outras, com a participação de todas em atividades festivas e culturais da escola, o que proporciona também um rico aprendizado das crianças típicas que passam a conviver com a diversidade, respeitando as diferenças e se tornando desde cedo responsáveis pela construção de uma sociedade mais justa e acolhedora:

... eles queriam ser pais dele, mães dele, queriam ser irmãos dele!...; ... as crianças começaram a ver que existe diversidade entre as pessoas e isso tem ajudado na questão da aceitação do outro com suas diferenças... (E4), (E5).

\section{"Não é por minha causa que a inclusão escolar não acontece"}

Nesta categoria vemos as barreiras encontradas pelas educadoras em seu cotidiano e também a tematização de assuntos recorrentes, que as isentavam dos problemas encontrados no processo de inclusão escolar. Quatro educadoras ressaltaram a necessidade de um mediador e seu próprio despreparo, o que prejudicava seu trabalho:

... a dificuldade tá é nisso é de não ter esse estagiário, essa pessoa pra acompanhar...; ... é preciso ter o cuidado de ter essa pessoa junto com o professor, porque senão o trabalho fica prejudicado...; ... a falta de estagiário é uma dificuldade muito grande...; ... os estagiários chegam às escolas sem muita noção do que irão fazer... (E4); (E5); (E1); (E2).

Uma professora apontou a dificuldade dada pela falta de apoio e preparo para lidar com a inclusão:

... eu não tenho nenhuma formação em inclusão...; ... como podemos receber os alunos de inclusão se não temos preparação para isso?... (E6)

As professoras também acreditam que as estratégias pedagógicas que aprenderam apenas podem ser aplicadas a crianças típicas. Este fato sugere que não entendem que talvez as crianças com deficiência apresentem também uma dificuldade em aprender o conteúdo em função da forma como este é transmitido.

... não é da minha formação... como motivar, como exercitar?...; não temos uma faculdade só de inclusão... (E7); (E1).
Outra questão que aparece como barreira externa é a falta de apoio entre os profissionais que acompanham a criança NEE, seja dentro, seja fora da escola:

... a gente faz o possível na sala de aula, mas não tem outro profissional que pode orientar...; ... eu queria participar mais das outras terapias dele, que ele tem a Terapia Ocupacional, fono, psicóloga... eu não sei o que ele tem lá. (E8).

As professoras apontam também problemas estruturais, tais como: o número muito grande de alunos em sala, o que dificulta o trabalho individualizado com a criança com deficiência. Fato exposto pela fala de uma professora:

... esses movimentos mais especificos que a gente não consegue em sala de aula, justamente porque a quantidade de alunos é bem maior... (E9)

A falta de diálogo e aceitação da família também foi um fator recorrente na opinião das professoras como barreira externa para a inclusão escolar:

... é importante a família aceitar a deficiência da criança e entender que sua criança tem limitações...; ... ele falta muito, principalmente depois que eu marquei uma reunião com a mãe, que eu pontuei as questões do G., que eu falei que ele precisava de acompanhamento...; ... a familia da criança que não entende que a criança necessita de um acompanhamento especifico... (E7); (E1); (E6).

\section{"Eu faço a minha parte"}

Algumas educadoras descreveram um olhar individualizado para as crianças com NEE:

... pensando sempre na criança como sujeito construtor de conhecimentos, cada um no seu ritmo, com diferentes capacidades e habilidade... (E4)

Elas também tentam respeitar as limitações e enfatizar as habilidades dessas crianças utilizando os diversos espaços físicos (biblioteca, sala de vídeo, parquinho de areia, arena), muitos recursos pedagógicos e a boa acessibilidade arquitetônica que a escola oferece, como se observa no trecho abaixo:

... temos jogos pedagógicos e de encaixe e desencaixe, da memória, massinha, quebra-cabeça, dominó, temos 
o gaiolão, aquele que possui dois escorregadores... o parquinho com os brinquedos... temos o velotrol... a pracinha, o vídeo... televisão... as salas de multimeios. (E1)

Outra estratégia utilizada pelas educadoras é tentar estabelecer um relacionamento de parceria com a família, na busca de uma compreensão de suas expectativas, de seu cotidiano e suas angústias:

... o pai me falou o grau dele, e eu fui colocando para o pai e o pai foi colocando pra mim, então essa troca foi muito marcante... (E7)

\section{DISCUSSÃO}

O presente estudo apresentou resultados sobre o processo de inclusão escolar em uma unidade municipal de educação infantil do município de Belo Horizonte, baseando-se na visão das educadoras.

Pode-se perceber que na categoria "A inclusão sobre diversos olhares", as educadoras restringem o conceito de inclusão a inserir uma criança especial na escola regular, para que elas convivam juntas em um mesmo ambiente. Entretanto esse espaço também deve possibilitar que todas as crianças aprendam juntas e com qualidade, em salas de aula provedoras de recursos e oportunidades $^{13}$.

Outro aspecto abordado foi a necessidade de um diagnóstico clínico para traçar um plano educacional; tal pensamento demonstra que a lógica do atendimento especializado precede o escolar: a maioria dos professores acredita que para receber um aluno da escola especial em sua sala necessita do acompanhamento de profissionais especializados por não saber lidar com esses alunos, por não serem dessa área... ${ }^{14}$. Contudo sabe-se que somente a deficiência da criança não é capaz de incapacitá-la. Esse aspecto foi apontado tanto por Vygotsky ${ }^{4}$ como no estudo de Ide et al. ${ }^{6}$, em que os dados relativos às dificuldades encontradas pelas crianças com NEE indicam que tais problemas não estavam diretamente relacionados às deficiências das crianças matriculadas nas escolas ou de seus quadros clínicos, mas, sim, a todo o contexto educacional.

Um traço positivo levantado nessa categoria foi a maior valorização da convivência, por parte dos educadores, entre crianças com NEE e as demais, como aspecto que favorece o desenvolvimento global de todas e promove a socialização entre elas. Essa convivência, desde as primeiras experiências na escola, pode contribuir para que haja uma diminuição de atitudes discriminatórias ${ }^{6}$.

Na segunda categoria, "Não é por minha causa que a inclusão escolar não acontece", as educadoras procuram apontar fatores que servem como barreiras, tanto para a criança quanto para o professor, no processo de inclusão escolar. O número insuficiente de professores auxiliares ou estagiários, contratados especialmente para acompanharem o aluno com NEE, foram citados como tais barreiras tanto nesse estudo como em Ide et al. ${ }^{6}$.

Outro fator indicado é a falta de formação continuada de professores, pois, apesar de ser um percurso para o início de uma mudança no contexto educacional, é necessário também sensibilizar as pessoas que ocupam cargos de direção, para que a educação inclusiva se estabeleça como um processo de mudança.

As professoras também acreditam que as estratégias pedagógicas que elas aprenderam apenas podem ser aplicadas a crianças típicas. Este fato sugere que as educadoras não entendem que talvez as crianças deficientes apresentem também uma dificuldade em aprender o conteúdo em função da forma como este é transmitido. Cabe aos profissionais da educação considerar as possibilidades singulares de cada criança, atentando para o que ela já conhece e o que pode fazer sozinha, seu nível de desenvolvimento real. Pois é o educador quem vai construir, em conjunto com seus alunos, as estratégias de compensação ${ }^{15}$. Nenhum método de ensino dá conta, por si só, da variedade de experiências e comportamentos dos alunos. Adequar o processo às necessidades dos educandos é um importante fator para o sucesso da aprendizagem e da inclusão.

Outra dificuldade encontrada pelo professor foi quanto ao ambiente escolar, no que diz respeito ao grande número de alunos em sala de aula. Tal aspecto parece demonstrar como um fator não diretamente relacionado à criança com NEE pode interferir em seu processo de ensino-aprendizagem e de inclusão escolar; assim como a estrutura escolar, materiais adaptados, ou seja, o ambiente funcionando como barreira nesses processos. O ambiente escolar diz respeito ao espaço físico e às relações sociais estabelecidas na escola, onde as crianças realizam suas atividades; dentre estas, estão não só as atividades escolares, mas também as da vida diária, como alimentação, higiene e vestuário, e as atividades lúdicas e de socialização. Esse ambiente, consequentemente, tem grande influência no desenvolvimento global dessas crianças ${ }^{6}$.

Nesta categoria foi levantada também a importância da participação da família no processo de inclusão escolar. A construção de uma sociedade inclusiva deve 
começar na família e ter sua contribuição na escola e na sociedade, uma vez que a formação do cidadão começa em casa, onde valores, hábitos e ideias sobre as coisas e o mundo são desenvolvidos. É na família que aprendemos a nos relacionar com os outros ${ }^{16,23}$. De acordo com Costabile e Brunello ${ }^{17}$, a família é grande parceira para o desenvolvimento da criança e deve atuar em conjunto com a escola. Deve ser a maior observadora das limitações e habilidades que a criança tem no processo de inclusão, sendo fundamental o diálogo entre a escola e os familiares. Entretanto ressaltam que em ocasiões nas quais a família encontra-se pouco envolvida ou ausente no processo de inclusão, a escola poderia auxiliá-la na conscientização da NEE da criança, pois algumas famílias não conseguem aceitar a deficiência.

$\mathrm{Na}$ última categoria, "Eu faço a minha parte", valoriza-se o que as educadoras têm feito para que a inclusão escolar aconteça. Algumas tentam potencializar as capacidades das crianças e aproveitar os recursos que a escola oferece, enfatizando que o papel do professor é fundamental por não se tratar apenas de repassar o conhecimento e, sim, a sua responsabilidade com o aprendizado do alunos.

As educadoras também buscam uma parceria com a família por compreenderem que, para a inclusão escolar acontecer, é necessário um trabalho em parceria com os diversos atores envolvidos no processo: os pais, a escola, outros profissionais e, finalmente, as próprias crianças. Segundo Vygotsky ${ }^{4}$, o processo de construção conjunta e contínua do conhecimento passa a ser um caminho para a superação das dificuldades.

\section{A CONTRIBUIÇÃO DA TERAPIA OCUPACIONAL NA ESCOLA}

O terapeuta ocupacional, por se dedicar ao estudo do desenvolvimento humano e ao processo de aprendizagem e autonomia, encontra-se munido de arcabouço teórico e prático, da práxis, para contribuir para a desmistificação da abordagem ao indivíduo com $\mathrm{NEE}^{18}$. Pensando no papel do terapeuta ocupacional no espaço escolar, Santos et al. ${ }^{19}$ colocam três enfoques: viabilizar o processo de inclusão por meio de assessoria ao professor e aos membros da comunidade; atender às necessidades e temores da criança e da família, e o enfrentamento para a mudança de paradigma médico para o educacional, ou seja, desconstruir o enfoque médico que vem atrelado à deficiência.

Lourenço e $\mathrm{Cid}^{20}$ realizaram uma busca em publicações na área sobre intervenções da Terapia
Ocupacional na educação infantil, e foram encontrados seis estudos que apresentavam formas de atuação da profissão nessa etapa da educação. As autoras concluíram que a Terapia Ocupacional está envolvida na promoção do desenvolvimento e do aprendizado de qualquer aluno, com ou sem deficiência. Essa promoção pode ocorrer por meio da participação na formação dos profissionais da comunidade escolar, da reestruturação de ambientes e da adaptação específica, assim como outras formas de intervenção que visem à melhoria do aprendizado das crianças. No ambiente escolar é possível promover o combate de atitudes segregacionistas e discriminatórias, não só com a participação dos educadores, mas considerando a necessidade de uma equipe com diversos profissionais, de modo a oferecer suporte aos alunos, família e comunidade ${ }^{19}$. Entre esses profissionais, o terapeuta ocupacional se destaca pela sua capacidade de favorecer a funcionalidade das potencialidades de cada indivíduo, atuando como um facilitador da inclusão, além de mediar a relação entre família e escola, com o objetivo de propor melhora no desenvolvimento da criança não apenas relacionado às necessidades educacionais especiais, mas também à vida diária do aluno fora da escola.

\section{CONCLUSÃO}

De acordo com os dados encontrados no estudo, pode-se analisar o quanto a concepção de professores acerca do processo de inclusão é indispensável para identificar seus facilitadores e suas barreiras, levando em conta o contexto que eles vivem. Os resultados desse estudo, como no estudo de Ávila et al. ${ }^{15}$, revelam a necessidade de se criar novas estratégias que proporcionem a reflexão dos professores sobre as crenças que intervêm em suas aprendizagens.

$\mathrm{Se}$ apenas a formação profissional fosse $\mathrm{o}$ fator determinante para a inclusão escolar de crianças deficientes, cursos seriam suficientes. Entretanto o que se viu neste estudo é que os conceitos das educadoras muitas vezes subestimam as competências desses alunos e muitas acreditam que apenas o fato das crianças estarem frequentando uma escola regular é o bastante.

A inclusão traz à tona a emergência da transformação da realidade social e escolar, que exige a reformulação de paradigmas, no que a escola passa a ocupar um papel ímpar em acolher e contribuir para a construção de um sujeito em desenvolvimento, por meio de cursos de atualização que facilitem a criação de estratégias individuais de acordo com a necessidade de cada criança. E para isso é necessário um espaço de interlocução com palestras, rodas de conversas, oficinas entre educadores e outros profissionais como: 
terapeutas ocupacionais, assistentes sociais, psicólogos, entre outros - além de pais, comunidade e também as crianças com NEE e típicas, para que cada um possa contribuir e se responsabilizar por um processo que vai além do campo educação, envolvendo a saúde e a sociedade.

É nesse processo que os terapeutas ocupacionais procuram atuar como facilitadores. A Terapia Ocupacional é uma profissão da área de saúde que, em interface com a área de educação, busca orientar, sensibilizar e criar estratégias de inclusão baseadas em seu conhecimento dentro das especificidades do desenvolvimento, no fazer humano, na autonomia, na aprendizagem, na acessibilidade, na ergonomia e nas oportunidades de integração social. Suas ações devem focar a potencialização da participação do aluno com NEE nos diversos contextos e atividades escolares, facilitando seu desempenho nessas atividades e estimulando-o em sua independência e autonomia. As possibilidades de atuação desse profissional incluem: capacitação do professor e da equipe escolar, intervenções voltadas para adaptação do ambiente físico, seleção e uso de recursos de tecnologia assistiva para facilitar a realização das diversas atividades escolares, prática de comunicação suplementar e/ou alternativa e informática ${ }^{21}$.

Portanto os resultados apresentados neste estudo poderão contribuir também para a reflexão sobre as possibilidades de ações que visem à melhoria da atenção especializada da Terapia Ocupacional à criança na perspectiva da educação inclusiva. Acredita-se que ações construídas coletivamente sejam um caminho mais eficiente, que possam resultar em práticas que atendam às demandas de cada indivíduo, garantindo assim seus direitos.

Desta forma, espera-se a mudança de paradigma na sociedade, a fim de criar uma filosofia de inclusão escolar e social que proporcione uma sociedade em que todas as crianças tenham garantidos seus direitos à educação e ensino de qualidade. Em uma sociedade inclusiva, as diferenças sociais, culturais e individuais são utilizadas para enriquecer as interações e a aprendizagem entre os seres humanos. Trata-se de uma mudança profunda no comportamento e na atitude das pessoas ${ }^{22}$.

\section{REFERÊNCIAS}

1. Declaração de Salamanca: sobre princípios, políticas e práticas na área das necessidades educativas especiais; 1994 [citado em 20 abr. 2011]. Disponível em: http://portal.mec. gov.br/seesp/arquivos/pdf/salamanca.pdf.

2. Abenhaim E. Os caminhos da inclusão: breve histórico. In: Machado AM. Neto AJV, Silva MVO, Prieto RG, Rannã W, Abenhaim E. Psicologia e direitos humanos: educação inclusiva, direitos humanos na escola. 2a ed. São Paulo: Casa do Psicólogo; 2005. p.39-53.

3. Abe PB, Araújo RCT. A participação escolar de alunos com deficiência na percepção de seus professores. Rev Bras Educ Espec. 2010;16(2):283-96. DOI: http://dx.doi.org/10.1590/ S1413-65382010000200009.

4. Vygotsky LS. A formação social da mente. São Paulo: Martins Fontes; 1998.

5. Crochík JL, Freller C, Dias, MAL, Casco R, Nascimento RB, Feffermann M. Atitudes de professores em relação à educação inclusiva. Psicol Cienc Prof. 2009;29(1):40-59. DOI: http://dx.doi.org/10.1590/S141498932009000100005.

6. Ide MG, Yamamoto BT, Silva CCB. Identificando possibilidades de atuação da Terapia ocupacional na

inclusão escolar. Cad Ter Ocup UFSCar. 2011;19(3): 323-32. DOI: $10.4322 /$ cto.2011.004.

7. Rocha EF, Luiz A, Zulian MAR. Reflexões sobre as possíveis contribuições da terapia ocupacional nos processos de inclusão escolar. Rev Ter Ocup Univ São Paulo. 2003;(14)2:72-8. DOI: http://dx.doi.org/10.11606/ issn.2238-6149.v14i2p72-78.

8. Glat R, Magalhães EFCB, Carneiro R. Capacitação de professores: primeiro passo para uma educação inclusiva. In: Marquezine MC, organizadora. Perspectivas multidisciplinares em educação especial. Londrina: Ed. UEL; 1998. p.373-8.

9. Tesini SFE, Manzini EJ. Perspectivas de professores que trabalham com deficientes mentais sobre a proposta de inclusão na rede oficial de ensino. In: Manzini EJ. Integração do aluno com deficiência: perspectiva e prática pedagógica. Marília: Ed. UNESP; 1999. p.85-96.

10. Fontanella BJB, Ricas J, Turato ER. Amostragem por saturação em pesquisas qualitativas em saúde: contribuições teóricas. Cad Saúde Pública. 2008;24(1):17-27. DOI: http:// dx.doi.org/10.1590/S0102-311X2008000100003. 
11. Campos CJG, Turato ER. Análise de conteúdo em pesquisas que utilizam metodologia clínico-qualitativa: aplicação e perspectivas. Rev Latino-Am Enfermagem. 2009;17(2):259-64. DOI: http://dx.doi.org/10.1590/S010411692009000200019.

12. Turato ER. Tratado da metodologia da pesquisa clínicoqualitativa. 3a ed. Petrópolis: Vozes; 2008.

13. Stainback S, Stainback W. Inclusão: um guia para educadores. Porto Alegre: Artes Médicas Sul; 1999.

14. Pedroso TMG. Educação especial da criança autista e psicótica: referenciais teóricos e as práticas pedagógicas. Rio de Janeiro; 1995.

15. Ávila CF, Tachibana M, Vaisberg TMJA. Qual é o lugar do aluno com deficiência: imaginário coletivo de professores. Paidéia. 2008;18(39):155-64. DOI: http://dx.doi. org/10.1590/S0103-863X2008000100014.

16. De Paula AR, Costa, CM. A hora e a vez da família em uma sociedade inclusiva. São Paulo: Sorri; 2006. Disponível em: http://www.sorri.com.br/sites/default/files/Cartilha\%20 -\%20A\%20hora $\% 20$ e $\% 20 \mathrm{a} \% 20 \mathrm{vez} \% 20 \mathrm{da} \% 20$ familia $\% 20$ -\%20SORRI-BRASIL.pdf.

17. Costabile C, Brunello MI. Repercussões da inclusão escolar sobre o cotidiano de crianças com deficiência: em estudo a partir do relato de famílias. Rev Ter Ocup. Univ. São Paulo. 2005;16(3):124-30. DOI: http://dx.doi.org/10.11606/ issn.2238-6149.v16i3p124-130.

Recebido para publicação: 11.03.14

Aceito para publicação: 27.05.15
18. Munguba MC. Inclusão Escolar. In: Cavalcanti A, Galvão C. Terapia Ocupacional: fundamentos e prática. Rio de Janeiro: Guanabara Koogan, 2007. p.519-25.

19. Santos FV, Cardoso PT, Matsukura TS. Inclusão escolar: Identificando a produção de conhecimento e práticas de terapeutas ocupacionais. In: Congresso Brasileiro de Educação Especial, Universidade Federal de São Carlos, São Carlos, 2-5 dez. 2008.

20. Lorenço GF, Cid MFB. Possibilidades de ação do terapeuta ocupacional na educação inclusiva. Cad Ter Ocup. UFSCar. 2010;18(2):169-79. Disponível em: http:// www.cadernosdeterapiaocupacional.ufscar.br/index.php/ cadernos/article/view/352/283

21. Barbosa MML, Silva SB. A terapia ocupacional no contexto escolar: uma ação conjunta com o professor para a inclusão da criança com deficiência. Belo Horizonte; 2007

22. Brasil. Ministério Público Federal. Fundação Procurador Pedro Jorge de Melo e Silva, organizadores. O acesso de alunos com deficiência às escolas e classes comuns da rede regular 2a ed. rev. e atual. Brasília: Procuradoria Federal dos Direitos do Cidadão; 2004. Disponível em: http://www.prgo. mpf.gov.br/cartilha_acesso_deficientes.pdf

23. Paula AR, Costa CM. A hora e a vez da família em uma sociedade inclusiva. Brasília: Ministério da Educação: Secretaria de Educação Especial, 2007. p.36. Disponível em: http://www.sorri.com.br/sites/default/ files/Cartilha $\% 20-\% 20$ A $\% 20$ hora $\% 20 \mathrm{e} \% 20 \mathrm{a} \% 20 \mathrm{vez} \% 20$ da\%20familia\%20-\%20SORRI-BRASIL.pdf 